Part of Journal of Research of the National Bureau of Standards, Volume 18, June 1937

\title{
BEHAVIOR OF LEATHER IN THE OXYGEN BOMB
}

\author{
By Joseph R. Kanagy
}

ABSTRACT

The effect on leather of exposure in the oxygen bomb under various conditions was studied. The conditions varied were pressure of oxygen, temperature in the bomb, duration of exposure, and the moisture content and $\mathrm{pH}$ of the leathers. A comparison is given between natural aging and accelerated aging in the bomb. An explanation based on the probable structures of quebracho and chestnut tannins is suggested for the difference in stability of the two types of leather. Comparative values of stability to exposure were obtained for leathers tanned with chestnut, quebracho, chrome, and a commercial leather tanned with a blend of vegetable tannins.

\section{CONTENTS}

I. Introduction

II. Materials and methods

III. Experimental results __... 715

1. Effect of varying the oxygen pressure in the bomb

2. Effect of varying the temperature of the bomb_......... 716

3. Effect of duration of exposure in the bomb

4. Effect of varying the moisture contents of the leathers......... 716

5. Effect of varying the $\mathrm{pH}$ of the leathers $\ldots$

6. Comparative rates of the evolution of carbon dioxide from chestnut and quebracho leathers _._. 718

IV. Discussion_..... 718

V. Summary

VI. References

\section{INTRODUCTION}

A study of the effect of oxygen on leather is important because the vegetable tannins which may constitute up to 50 percent of the weight of a finished leather are easily oxidized. J. Jany $[1]^{1}$ measured the amount of oxygen absorbed at atmospheric pressure by tanning materials and found that the amount absorbed increased with an increase in $\mathrm{pH}$. He also found that pyrogallol absorbed more oxygen than phenol, this fact supporting the theory that the oxidation depends upon the number of hydroxyl groups. E. W. Merry [2] verified Jany's results. He made further experiments to show that the amount of oxygen absorbed depended upon the type of tanning material and that the presence of metals, such as iron and especially copper, also increased the absorption of oxygen. The fact that iron accelerates the absorption of oxygen and that the amount absorbed increases with an increase in $\mathrm{pH}$ was later confirmed by W. Grassmann and F. Fohr [3].

\footnotetext{
1 Figures in brackets refer to references at the end of this paper.
} 
The present investigation consisted in a study of the deterioration of vegetable-tanned leathers in an atmosphere of oxygen under pressure as preliminary work for the development of an accelerated aging test for leather.

\section{MATERIALS AND METHODS}

A porcelain-lined oxygen combustion bomb, 5 inches deep and 3 inches in diameter, was used in this work. The quebracho- and chestnut-tanned leathers were prepared in the experimental tannery of the National Bureau of Standards and contained no filling materials except those taken up from the natural commercial extracts. Blocks of these leathers, 6 by 15 inches, which were treated with varying amounts of sulphuric acid so as to have initial $\mathrm{pH}$ values ranging from 5 to 2 , were cut into smaller pieces which conveniently fitted into the bomb.

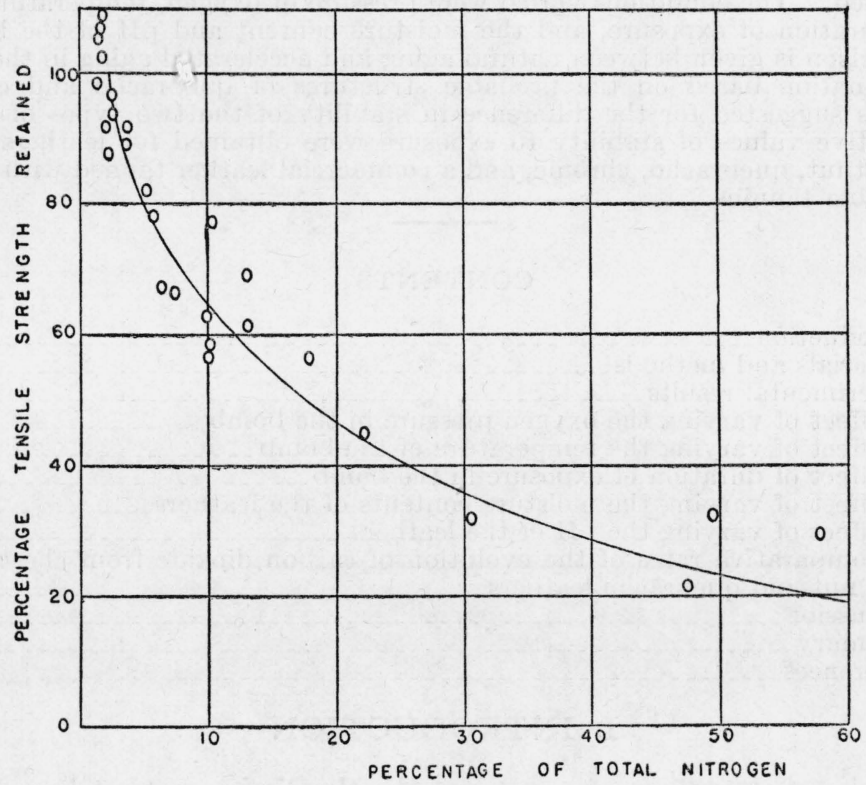

FIGURE 1.-Comparison of percentage of total nitrogen extracted and loss in tensile strength of leathers aged 2 years under natural conditions.

Since tensile strength tests could not be made on the small pieces used in the bomb, the effects of the various tests were determined by measuring the chemical deterioration of the leather. The leathers, after being exposed in the bomb, were ground and $3 \mathrm{~g}$ of each sample were extracted with five $30-\mathrm{ml}$ portions of water at $50^{\circ} \mathrm{C}$. Each portion of water remained in contact with the leather 20 minutes. After being extracted with water, each sample of leather was further extracted by the same procedure with five $30-\mathrm{ml}$ portions of $0.1 \mathrm{~N}$ sodium carbonate at room temperature. The total nitrogen contents of both the water and sodium carbonate extracts were determined by the Kjeldahl method and from the sum of the two measurements the percentage of the total nitrogen extracted was determined. This method of determining the amounts of soluble nitrogen compounds 
in leather is similar to that used by Frey and Beebe [4]. These percentages of the total nitrogen extracted are not a measure of the amount of oxidation occurring in the bomb, but represent the extent of the chemical deterioration in the hide substance under the different conditions of exposure. The mechanism of this deterioration has not yet been studied.

The change in tensile strength with chemical deterioration from results of previous work [5] is shown in figure 1. The percentage tensile strength retained by eight lots of leather was plotted against the total nitrogen extracted from these leathers. The loss in tensile strength is quite rapid at first in comparison with the amount of total nitrogen extracted. However, the results show that a general correlation exists between the physical and chemical deterioration, and for this reason a measurement of chemical deterioration should be as significant as a measurement of physical deterioration.

\section{EXPERIMENTAL RESULTS}

\section{EFFECT OF VARYING THE OXYGEN PRESSURE IN THE BOMB}

Preliminary experiments showed that only slightly more deterioration occurred when the oxygen pressure was increased from 50 to 100

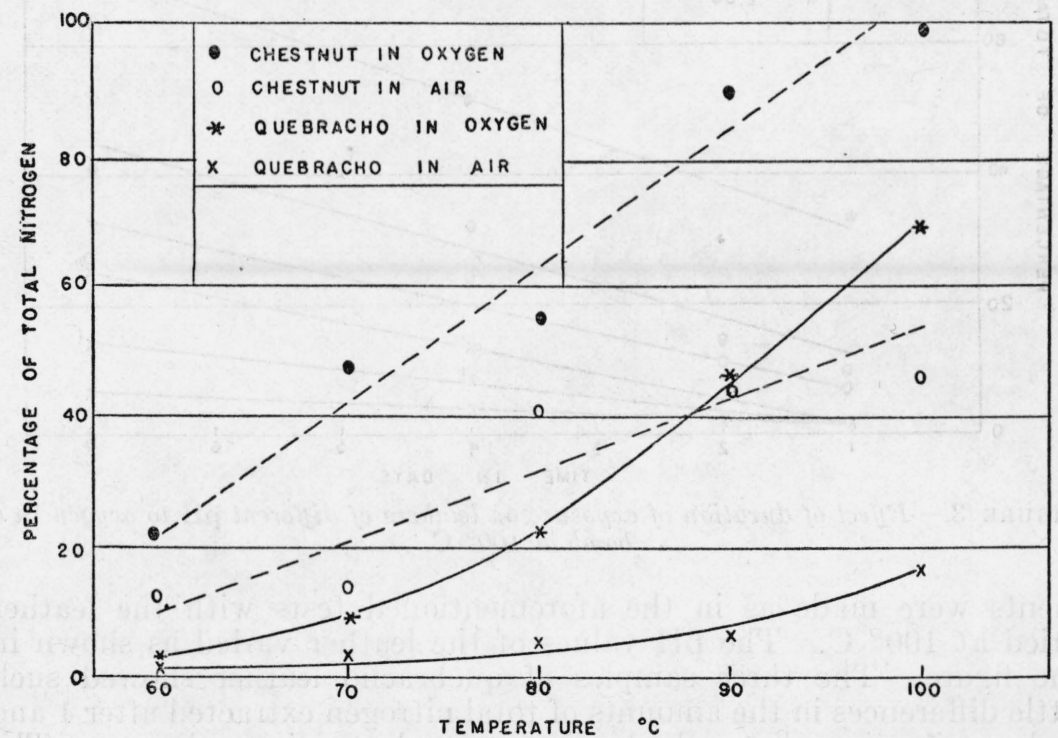

FIGURE 2.-Effect of varying the temperature on the amount of total nitrogen extracted from leathers at $\mathrm{pH} 2.5$ when exposed to air in an oven and to oxygen in a bomb.

pounds. For this reason the initial pressure of oxygen was held as near to 100 pounds as possible in making all the tests. Two sets of samples at $\mathrm{pH}$ values of approximately 2.5 were placed in an electric oven at specified temperatures varying from 60 to $100^{\circ} \mathrm{C}$ for 24 hours. At the end of this time one set of the samples was placed in the bomb and aged at 100-lb oxygen pressure at the same temperature for 1 week, the other set being allowed to remain in the oven in contact 
with air at the same temperature for the same length of time. The effect on the samples of leather on exposure to oxygen in the bomb and on samples exposed to air in the oven is shown in figure 2.

\section{EFFECT OF VARYING THE TEMPERATURE OF THE BOMB}

The effect of varying the temperature from 60 to $100^{\circ} \mathrm{C}$ is also shown in figure 2. Chestnut leather shows considerably more deterioration than quebracho leather and the extent of the deterioration for both leathers increases continuously with increasing temperature.

\section{EFFECT OF DURATION OF EXPOSURE IN THE BOMB}

The increase in deterioration with duration of exposure is shown in figure 3 . The time intervals ranged from 1 to 7 days and the experi-

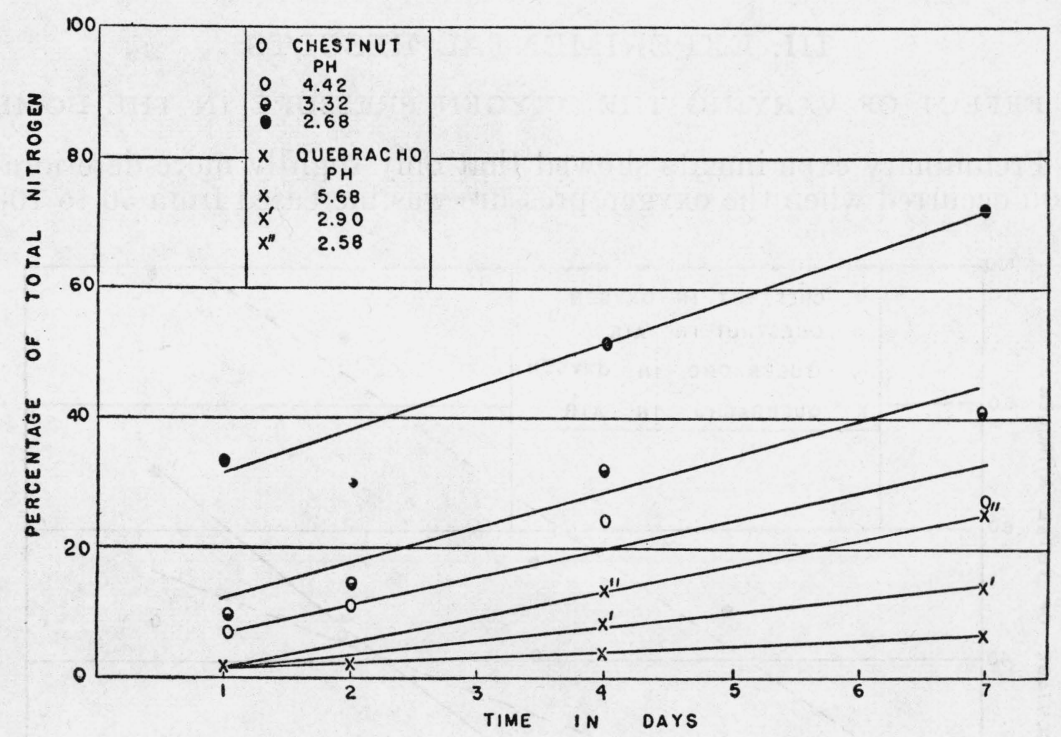

Figure 3.-Effect of duration of exposure on leathers of different $\mathrm{pH}$ to oxygen in a bomb at $100^{\circ} \mathrm{C}$.

ments were made as in the aforementioned tests with the leather dried at $100^{\circ} \mathrm{C}$. The $\mathrm{pH}$ values of the leather varied as shown in the figure. The three samples of quebracho leather showed such little differences in the amounts of total nitrogen extracted after 1 and 2 days of aging that only one point is plotted in each case. The deterioration increases at approximately a constant rate. The greater stability of the quebracho leather in comparison with the chestnut leather is again shown by these results.

\section{EFFECT OF VARYING THE MOISTURE CONTENTS OF THE LEATHERS}

Experiments on the effect of varying the moisture contents of leather aged in the oxygen bomb were all done at $70^{\circ} \mathrm{C}$. It was impossible to make tests at a higher temperature because of the tendency of the leather containing high amounts of moisture to char. Even at this 
temperature, the chestnut leather conditioned at 60 -percent relative humidity and aged 1 week was charred, so that it was impossible to obtain any significant results with it. Tests were made with dried leather and with leather conditioned at 30- and 60-percent relative humidity. The dried leather was obtained by heating the sample in an electric oven at $100^{\circ} \mathrm{C}$ for 24 hours. The conditioning at 30 - and 60 -percent relative humidity was done by placing the samples in a desiccator for 2 weeks over sulphuric acid solutions which produced these humidities. The moisture contents of these leathers were 10.8 and 14.3 percent, respectively. The percentages of total nitrogen extracted from leathers of different moisture contents and known $\mathrm{pH}$ are shown in figure 4.

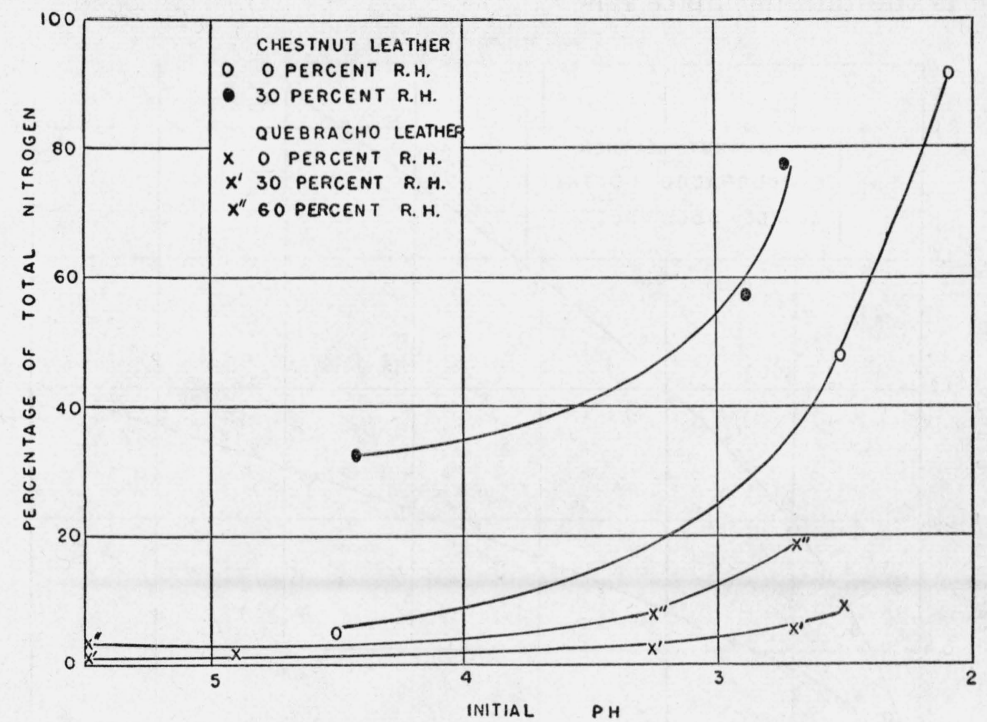

Figure 4.-Effect of varying the moisture contents and the $\mathrm{pH}$ on the deterioration of leathers in an oxygen bomb at $70^{\circ} \mathrm{C}$.

Chestnut leather shows a large increase in deterioration when the relative humidity is increased from 0 to 30 , and on increasing it further to 60 percent the samples charred as mentioned above. With quebracho leather there is no significant difference in the extent of deterioration at 0 - and 30 -percent relative humidity; however, an increase occurs in the samples conditioned at 60 percent.

\section{EFFECT OF VARYING THE $\mathrm{pH}$ OF THE LEATHERS}

The influence of $\mathrm{pH}$ of the leather on the deterioration produced in the oxygen bomb is shown in figures 3,4 , and 7 . The amount of deterioration in all cases increases with decreasing $\mathrm{pH}$. This increase is slow to about $\mathrm{pH} 3$, but it becomes rapid below this point. Chestnut leather shows large amounts of deterioration at comparatively high $\mathrm{pH}$ values. In general, the results in regard to the effect of $\mathrm{pH}$ are similar to those obtained by Bowker and Wallace [6] in a study of the effect of sulphuric acid on leather. 


\section{COMPARATIVE RATES OF THE EVOLUTION OF CARBON DIOXIDE FROM CHESTNUT AND QUEBRACHO LEATHERS}

In order to obtain a measure of the relative rates of the oxidation of chestnut and quebracho leathers, dry air free from carbon dioxide was passed over the samples in $U$-tubes at $100^{\circ} \mathrm{C}$, and the amounts of water and carbon dioxide given off were measured by leading the gases through a train of $U$-tubes containing magnesium perchlorate and Ascarite. The amounts of carbon dioxide evolved are shown in figure 5. Chestnut leather, as shown by the amounts of carbon dioxide given off, is more readily oxidized than quebracho leather. The failure to obtain carbon dioxide when hide substance was treated under the same conditions shows that the source of most of the carbon dioxide is the tanning materials.

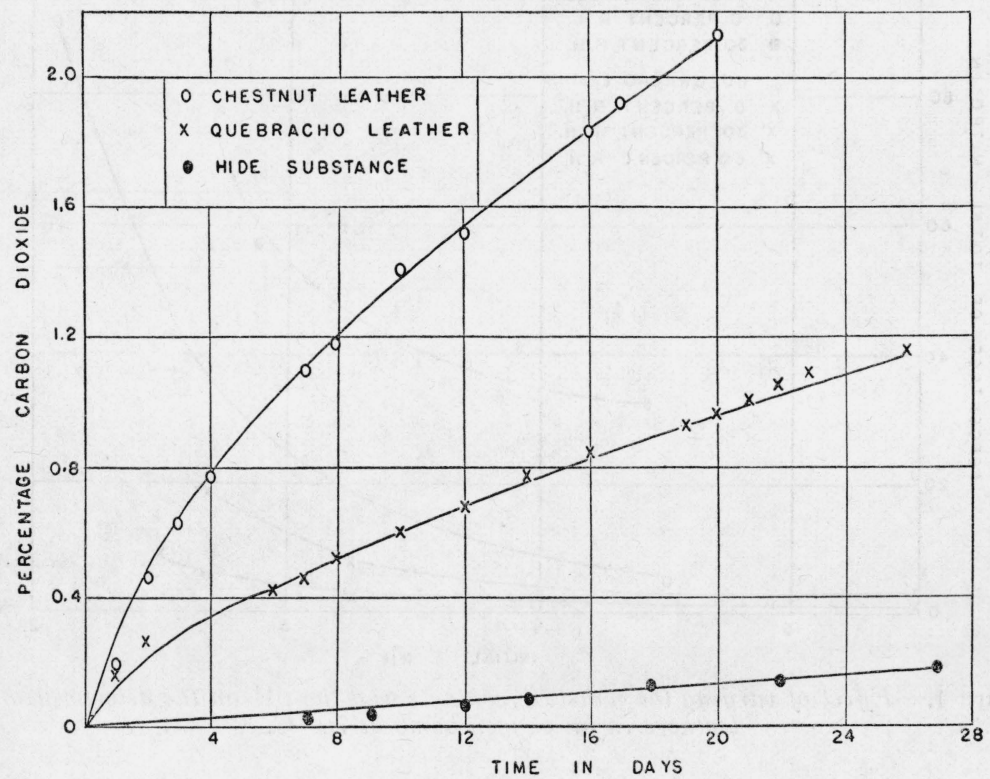

Figure 5.-Rates of evolution of carbon dioxide from chestnut and quebracho leathers when heated in a stream of air at $100^{\circ} \mathrm{C}$.

\section{DISCUSSION}

The results show a large difference between the stability of quebracho- and chestnut-tanned leathers to exposure in the oxygen bomb. Under these conditions the former is quite stable, while the latter is comparatively unstable. An explanation of this difference is suggested by a consideration of the probable structures of the two types of tannins. Chestnut tannin belongs to the pyrogallol type, while quebracho tannin is one of the catechol type. As pointed out by Jany [1], the pyrogallol type should be more easily oxidized because it contains a larger number of hydroxyl groups. Nass and Trimble [7] working independently obtained results which show that chestnut tannin may be considered similar to gallotannin. The formula of gallotannin as determined by Fischer [8] consists of five digallic acid 
molecules connected by ester linkages to one molecule of glucose giving the following structure, where $\mathrm{R}$ represents one digallic acid residue.<smiles>[R20]C([R20])[C@H]([R20])[C@H]([R20])[C@H]([R20])[C@H]([2H])C1COC1</smiles><smiles>CC(=O)C1CCC(O)C(OC(=O)C(CCO)CC(O)O)C1</smiles>

Gallotannin

Digallic acid residue

The gallotannin molecule is easily hydrolyzed because it contains many ester linkages. The glucose residue and the large number of hydroxyl groups make it susceptible to oxidation.

The structure of the catechol type of tannins, to which quebracho belongs, differs from that of the pyrogallol type. These tannins are believed to originate by polymerization and condensation from crystalline primary catechins which have the following structure [9]:<smiles>OCCC(CO)C1OC(CO)C(O)CC1O</smiles>

Catechin

This compound has no linkages which are readily hydrolyzed. The resorcinol and catechol residues in this compound are more stable toward oxygen than the pyrogallol residues in gallotannin. The fact that the catechol tannins may be formed by polymerization or condensation gives further evidence of stability.

Although a detailed procedure for an accelerated aging test is not recommended at this time, the results obtained in the present investigation parallel those obtained in natural aging, as shown in figures 6 and 7. In figure 6, the total nitrogen extracted from chestnut- and quebracho-tanned leathers, aged under natural conditions for 8 years, is plotted against $\mathrm{pH}$. Figure 7 shows the results obtained when the same types of leather were dried at $100^{\circ} \mathrm{C}$ for 24 hours, and aged for 1 week in the oxygen bomb at the same temperature. In each case chestnut leather shows more deterioration than the quebracho leather and the effect of $\mathrm{pH}$ is similar for both the accelerated and the naturally aged leathers, except for the fact that more deterioration takes place at the high $\mathrm{pH}$ values under the accelerated conditions.

The importance of time of aging for an accelerated test is shown in figure 3 . The differences between the amounts of the total nitrogen extracted from the three samples of quebracho leather of known pH increase with increased duration of exposure. The comparative 


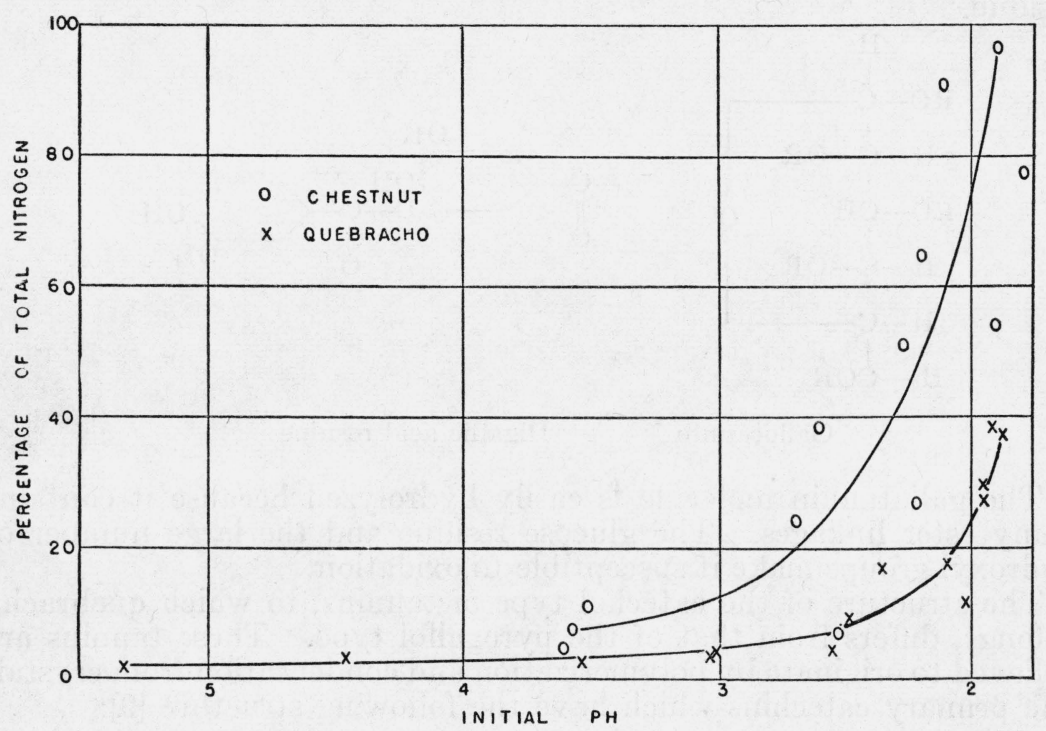

FIGURE 6.-Effect of aging under natural conditions for about 8 years on leathers of known $\mathrm{pH}$.

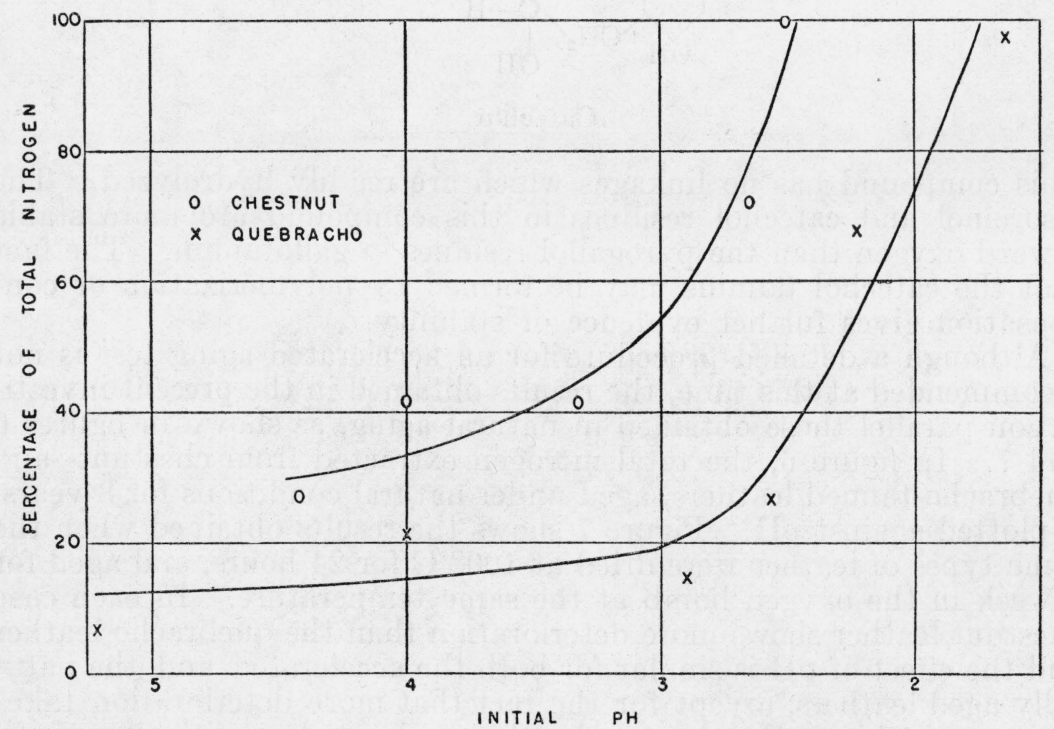

Figure 7.-Effect of accelerated aging for 7 days at $100^{\circ} \mathrm{C}$ on leathers of known $\mathrm{pH}$. 
values for such samples are therefore more significant for the longer times of exposure.

Comparative data on the stability of several types of leather when treated in the oxygen bomb were obtained. These leathers were tanned with chestnut, quebracho, chrome, and a commercial blend of vegetable tannins. The values were determined from the results of aging the oven-dried samples at $100^{\circ} \mathrm{C}$ for 1 week. The comparisons are given in table 1 , and the method of obtaining them is shown in figure 8. In this figure the total nitrogen extracted is plotted against the $\mathrm{pH}$, and the comparisons made at the constant $\mathrm{pH}$ value of 2.75 .

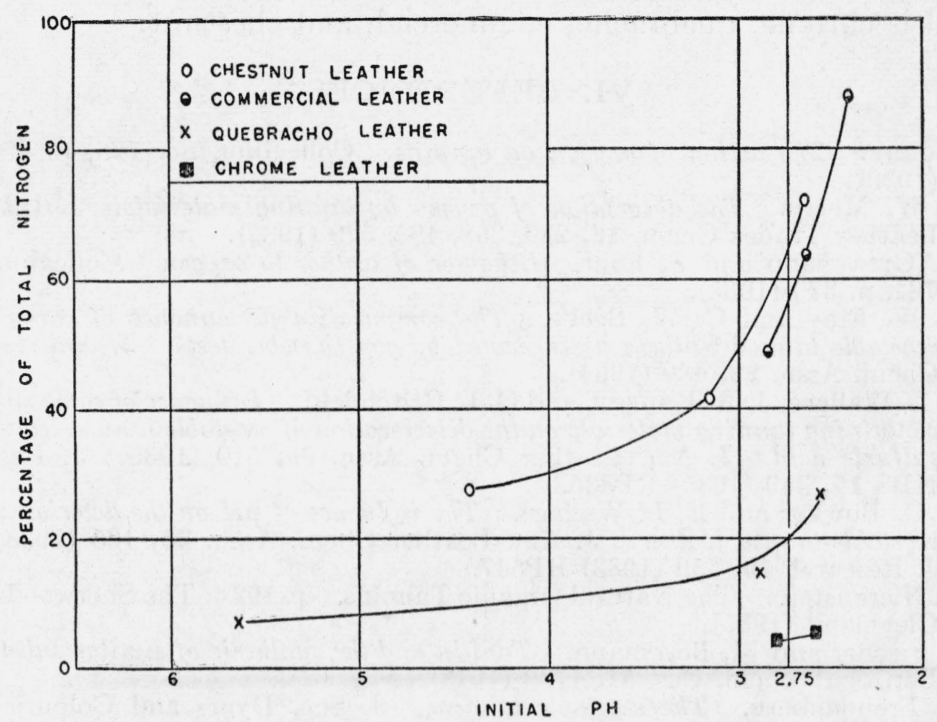

FIgURE 8.-Method used in obtaining comparative data of the stabilities of leather when exposed to oxygen in a bomb.

TABLE 1.-Comparative stabilities of leathers in the oxygen bomb

\begin{tabular}{|c|c|}
\hline Leather & \begin{tabular}{|c} 
Total \\
nitrogen \\
soluble \\
at pH \\
2.75
\end{tabular} \\
\hline $\begin{array}{l}\text { Chestnut } \\
\text { Commercial-..... } \\
\text { Quebracho-..... } \\
\text { Chrome.-........ }\end{array}$ & \begin{tabular}{r}
\multicolumn{1}{c}{$\%$} \\
64.8 \\
56.5 \\
19.8 \\
4.3
\end{tabular} \\
\hline
\end{tabular}

The selection of this $\mathrm{pH}$ is arbitrary and similar comparisons could be made at any other $\mathrm{pH}$. The most valuable information will probably be obtained by using this or some higher $\mathrm{pH}$. The comparisons point out the degree of protection offered to the leather by the different types of tanning materials. Chrome-tanned leather shows the greatest stability in the oxygen bomb, while the quebracho leather shows considerably more resistance to this treatment than either the chestnut or the commercial leather. 


\section{SUMMARY}

1. Deterioration of leather on treatment in the oxygen bomb increases with increase in oxygen pressure, temperature, duration of exposure, moisture content, and decrease in $\mathrm{pH}$.

2. Quebracho leather is considerably more stable under all conditions of treatment than chestnut leather.

3. Accelerated aging in an atmosphere of oxygen in a bomb compares favorably with natural aging except for the fact that under the former conditions more deterioration takes place at high $\mathrm{pH}$ values.

4. The order of decreasing stability of the different types of leather tested is chrome, quebracho, commercial, and chestnut.

\section{REFERENCES}

[1] J. Jany. The action of oxygen on tannins. Collegium, no. 726, p. 453-460 (1930).

[2] E. W. Merry. The absorption of oxygen by tanning materials. J. Int. Soc. Leather Trades Chem. 16, 239, 358, 489, 529 (1932).

[3] W. Grassmann and F. Fohr. Behavior of leather to oxygen. Collegium, no. 784, p. 379 (1935).

[4] R. W. Frey and C. W. Beebe. The comparative permanence of chrome and vegetable tanned leathers as indicated by gas chamber tests. J. Am. Leather Chem. Assn. F9, 489 (1934).

[5] E. L. Wallace, J. R. Kanagy, and C. L. Critchfield. Influence of some sulphurcontaining tanning materials on the deterioration of vegetable tanned leathers by sulfuric acid. J. Am. Leather Chem. Assn, 30, 510 (1935); J. Research NBS 15, 369 (1935) RP835.

[6] R. C. Bowker and E. L. Wallace. The influence of $p H$ on the deterioration of vegetable-tanned leather. J. Am. Leather Chem. Assn. 28, 125 (1933); BS J. Research 10, 559 (1933) RP547.

[7] M. Nierenstein. The Natural Organic Tannins. p. 192. The Sherwood Press, Cleveland (1935).

[8] E. Fischer and M. Bergmann. Tannin and the synthesis of similar substances. Ber. deut. chem. Ges. 51, 1760 (1918).

[9] K. Freudenberg. The vegetable tannins. J. Soc. Dyers and Colourists 45, 352 (1929).

Washington, April 2, 1937. 